U.S. Geological Survey and the California State Water Resources Control Board

\title{
Comparing Public-Supply and Shallow Aquifer Groundwater Quality in the North San Francisco Bay Aquifers, California
}

Groundwater provides more than $\mathbf{4 0}$ percent of California's drinking water. To protect this vital resource, the State of California established the Groundwater Ambient Monitoring and Assessment (GAMA) Program. The Priority Basin Project of the GAMA Program (GAMA-PBP) provides a comprehensive assessment of the State's groundwater quality and increases public access to groundwater-quality information.

\section{The North San Francisco Bay Study Units}

Groundwater quality in the North San Francisco Bay area Public-Supply and Shallow Aquifer Systems was investigated by the GAMA-PBP. The North San Francisco Bay PublicSupply Aquifer System study unit (NSF-PA) was sampled in 2004 (Kulongoski and others, 2010). The North San Francisco Bay Shallow Aquifer System study unit (NSF-SA) was sampled in 2012 (Bennett, 2018). The NSF-PA and NSF-SA largely coincide areally; however, they represent different parts of the aquifer system vertically. The NSF-PA examined deeper groundwater primarily used for public supply, whereas the NSF-SA examined relatively shallow groundwater primarily used for domestic supply. Both study units were divided into two study areas: (1) alluvium-filled groundwater basins called the Valleys and Plains study area and (2) volcanic, metamorphic, and ultramafic hard-rock highlands surrounding the Valleys and Plains called the Highlands study area (Bennett, 2018).

Groundwater-quality status and understanding assessments of the study units were chiefly based on data collected by the U.S. Geological Survey. In the NSF-PA, additional inorganic data came from the California State Water Resources Control Board Division of Drinking Water Public Supply Water-Quality Database (Kulongoski and others, 2010).

A grid-based site-selection method was used in both study units, which allowed for an estimation of the proportions of the groundwater resource having constituents at low, moderate, or high concentrations relative to regulatory and non-regulatory benchmarks for drinking-water quality established by the U.S Environmental Protection Agency (EPA) or California State Water Resources Control Board Division of Drinking Water. The grid-based method provides statistically unbiased results and permits comparison to other GAMA-PBP study areas (Belitz and others, 2010). NSF-SA grid well not included in
comparison with NSF-PA

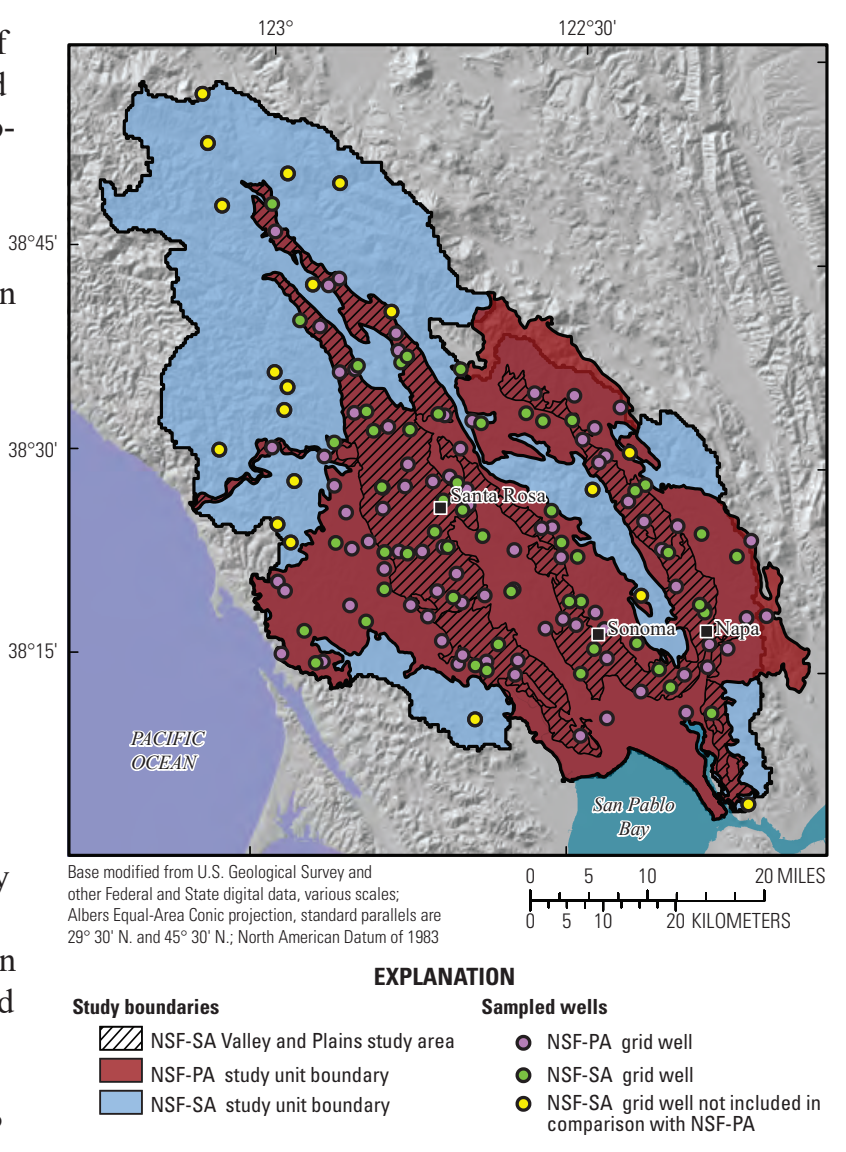

\section{DEFINITIONS}

\section{Public-Supply Aquifer System}

The GAMA-PBP defines the "public-supply aquifer system" as the depth zone that is tapped by publicsupply wells. Public-supply wells are generally drilled to deeper depths than domestic wells and are screened over large portions of the aquifer. Public-supply wells are constructed to produce high yields of groundwater.

\section{Shallow-Aquifer System}

The GAMA-PBP defines the "shallow" aquifer system as that part of an aquifer shallower than the productive zones of the public-supply aquifer. The shallow-aquifer system is generally used by domestic-well owners and small community systems. Domestic and small-system wells typically produce enough water to meet the needs of one to a few households and, as such, have relatively low yields compared to public-supply wells.

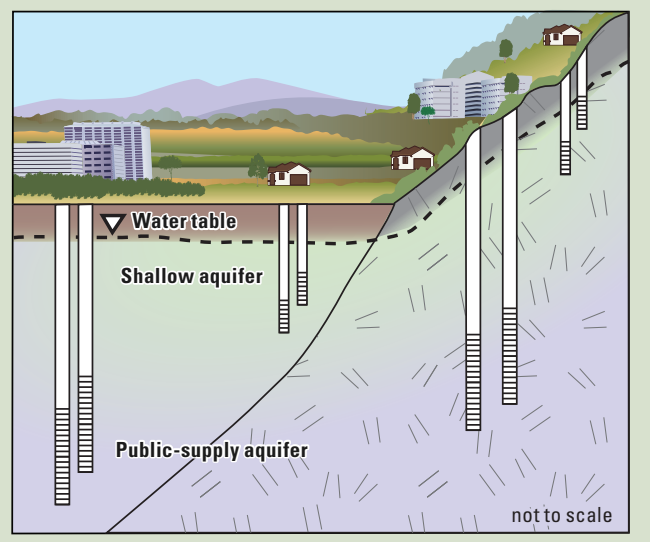

Figure showing a conceptual model of the difference between the Public-Supply and Shallow Aquifer Systems. 


\section{Comparison of Study-Unit Characteristics}

Characteristics of the NSF-PA and NSF-SA and their respective study areas (Highlands and Valleys and Plains in each) - specifically, well construction, groundwater age, and land use-were compared to identify differences that could affect interpretations of water-quality results. Further discussion of the differences among these and other characteristics between the NSF-PA and NSF-SA is presented in Bennett (2018).

\section{Well-Construction Comparison}

Well depth is an important variable and is often used when assessing a well's vulnerability to contamination. For the Valley and Plains study area, median well depth in the NSF-PA (303 feet; $\mathrm{ft}$ ) is significantly deeper than in the NSF-SA (172 ft), confirming that public-supply wells are generally deeper than domestic wells in the North San Francisco Bay area alluvial basins. There was less difference between median well depths in the NSF-PA and NSF-SA for the Highlands study area.

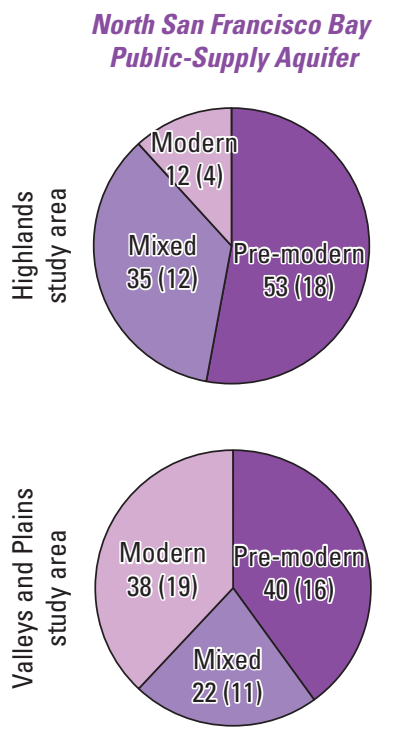

\section{North San Francisco Bay Shallow Aquifer}

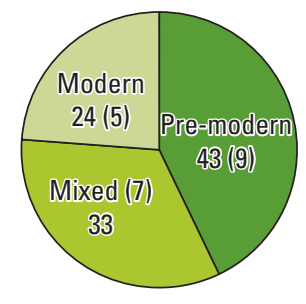

(The number in parentheses is the number of samples classified as modern, mixed, or pre-modern in each study area)

North San Francisco Bay Public-Supply Aquifer
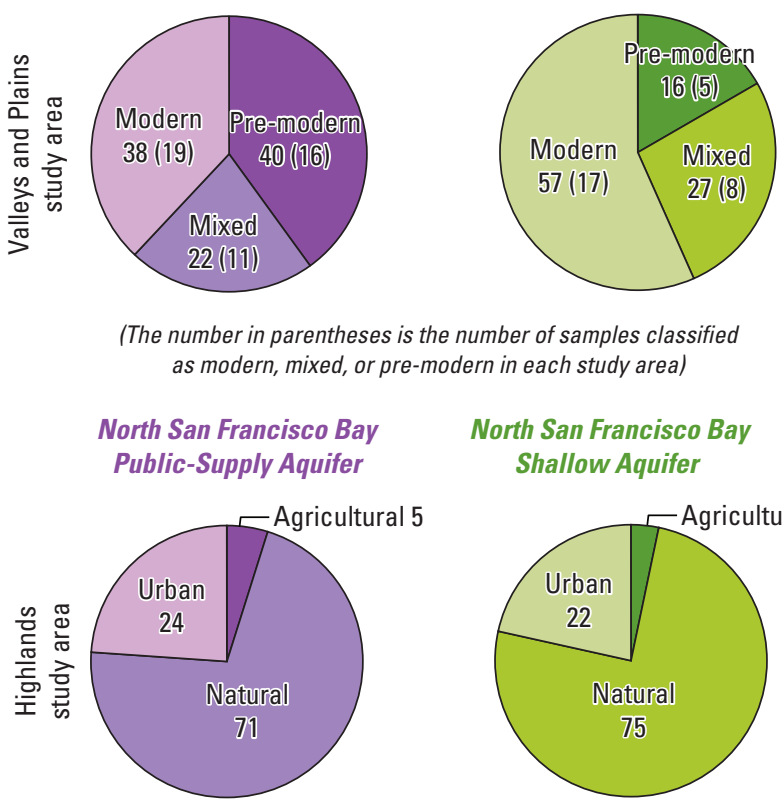

North San Francisco Bay Shallow Aquifer

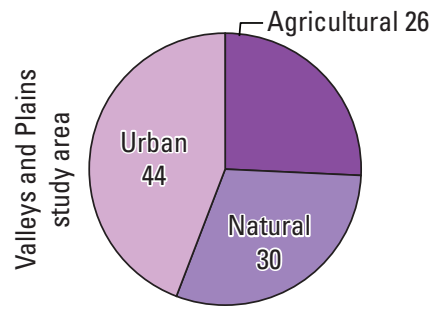

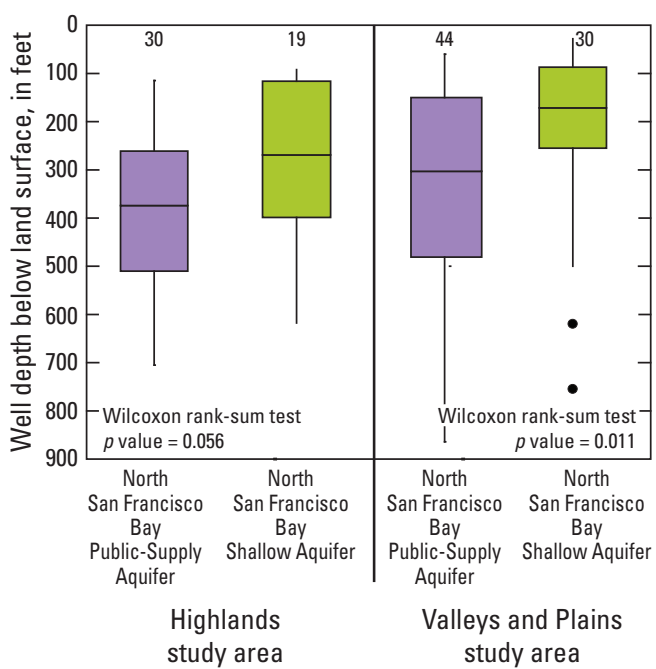

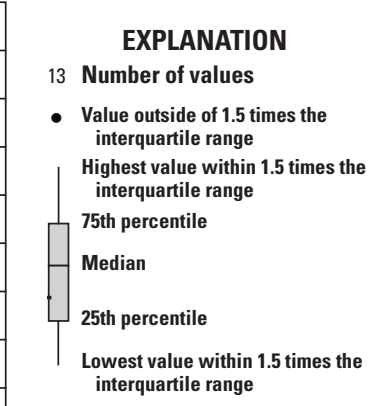

\section{Groundwater-Age Comparison}

The time required for water to travel from where it first enters the groundwater system to the well is the "residence time." A long residence time can allow for more chemical reactions between groundwater and the rocks and sediments of the aquifer, whereas a short residence time can permit contaminants introduced at the land surface to reach wells quickly. To compare residence times of samples from the NSF-PA and NSF-SA, a simplified age-classification system was constructed using tritium concentrations (Bennett, 2018). Tritium is a short-lived radioactive isotope of hydrogen with a half-life of 12.32 years and has been detected in our atmosphere in amounts that greatly exceed natural levels, as a result of aboveground nuclear-weapons testing that began in the mid-1950s. Groundwater samples were classified as pre-modern (tritium less than 0.2 tritium units), mixed (tritium greater than or equal to 0.2 and less than 1 tritium unit), or modern (greater than 1 tritium unit) in age on the basis of the tritium concentrations in the sample. A greater percentage of wells with groundwater identified as modern were observed in the NSF-SA than in the NSF-PA, both in the Valley and Plains and in the Highlands study areas. The significantly greater proportion of modern water in the NSF-SA was consistent with the generally shallower wells.

\section{Land-Use Comparison}

Land-use characteristics within a $1,640-\mathrm{ft}$ radius surrounding sampled wells were used to compare the NSF-PA and NSF-SA (Jin and others, 2013). In general, land use types for the study units were similar. This was expected, given that the study units overlap areally. The greater percentage of urban land use around wells in the NSF-PA, particularly in the Valleys and Plains, likely corresponds to public-supply wells being near population centers. 


\section{Overview of Water Quality}

GAMA's Priority Basin Project evaluates the quality of untreated groundwater. For context, however, benchmarks established for drinking-water quality are used for comparisons. The quality of drinking water can differ from the quality of groundwater because of contact with household plumbing, exposure to the atmosphere, or water treatment. Federal and California regulatory benchmarks for protecting human health (maximum contaminant level, MCL) are used when available. Otherwise, non-regulatory benchmarks for protecting human health (lifetime health advisory level, HAL) and non-regulatory benchmarks for protecting aesthetic properties, such as taste and odor (secondary maximum contaminant level, SMCL), were used.

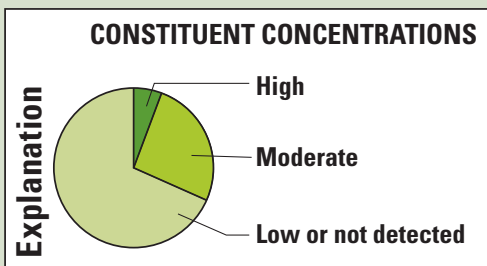

Values are a percentage of the area of the primary aquifers with concentrations in the three specified categories. $[<$, less than]

High, moderate, and low concentrations are defined relative to benchmarks

Concentrations are considered high if they are greater than a benchmark. For inorganic constituents, concentrations are moderate if they are greater than one-half of a benchmark.

For organic and special-interest constituents, concentrations are moderate if they are greater than one-tenth of a benchmark. Low concentrations include nondetections and values less than moderate concentrations. Methods for evaluating water quality are discussed by Bennett and Fram (2014).

\section{Comparison of Water Quality}

Proportions of the assessed groundwater resource having low, moderate, and high relative concentrations of constituent groups were compared to evaluate differences in water quality between the NSF-PA and NSF-SA. Differences in proportions can be compared graphically; however, observed differences do not always indicate statistical significance. To address this, statistical significance of the differences between the study units and study areas were tested using two-by-two contingency table tests. The significance level (p) used when testing these differences was based on a threshold value $(\alpha)$ of 10 percent $(\alpha=0.1)$. If the test statistic $p$ was less than $\alpha$, there was a statistically significant difference.

\section{Inorganic Constituents}

Inorganic constituents that have health-based benchmarks (HBB) were evaluated as classes (groups of common constituents) and as individual analytes for comparisons between the study units and study areas. Few significant differences were ultimately observed. Proportions of the studied area that have high relative concentrations of $(A)$ "any" inorganic constituent that have an HBB (a grouping of all inorganic constituents that have HBBs in one class), $(B)$ trace elements that have HBBs (as a class of their own), $(C)$ nitrate, and $(D)$ manganese were all significantly greater in the NSF-SA Valleys and Plains study area than in the NSF-PA Valleys and Plains study area.

The trace elements that most often contributed to high concentrations in the NSF-PA and NSF-SA were arsenic and manganese. For the Highlands, high concentrations were more common in the NSF-PA than in the NSF-SA, whereas for the Valleys and Plains high concentrations were more common in the NSF-SA. There are notable geothermal systems in the Valleys and Plains study area that contribute mineral-rich waters to some areas of the aquifer system (Forrest and others, 2013), which could explain the comparably high trace-element concentrations in the two units. $\begin{array}{cc}\text { North San Francisco Bay } & \text { North San Francisco Bay } \\ \text { Public-Supply Aquifer } & \text { Shallow Aquifer }\end{array}$

A. Any inorganic with HBB
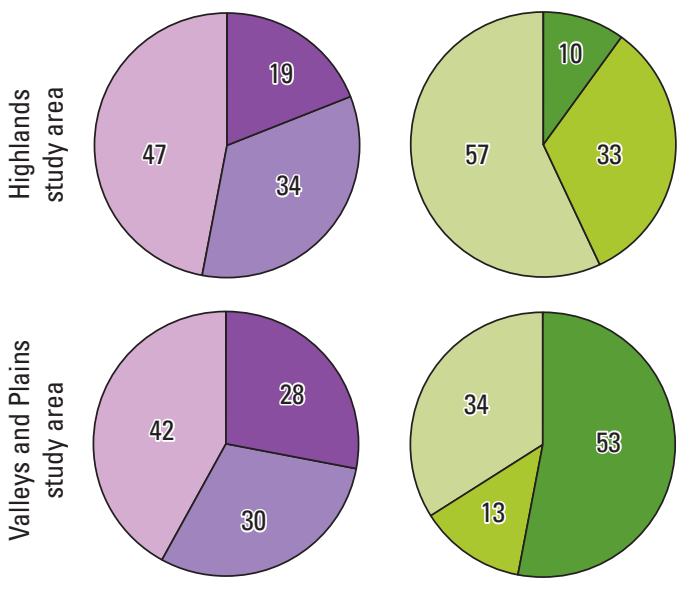

\section{Nitrate}
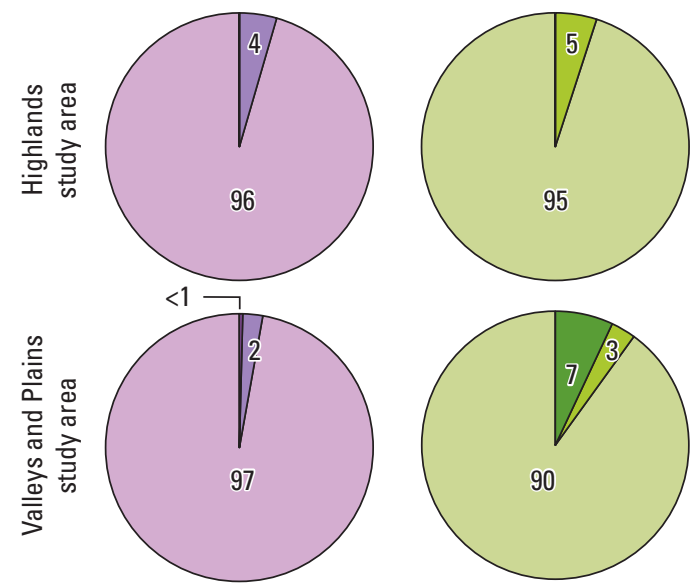

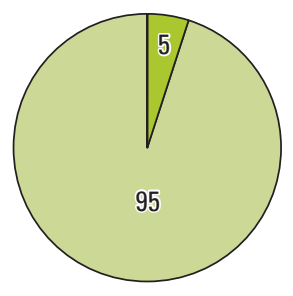

North San Francisco Bay Public-Supply Aquifer

$B$. Trace elements with HBB
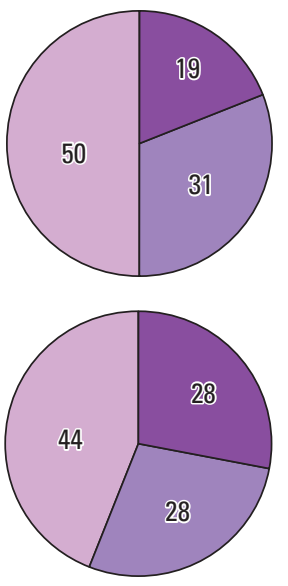

D. Manganese
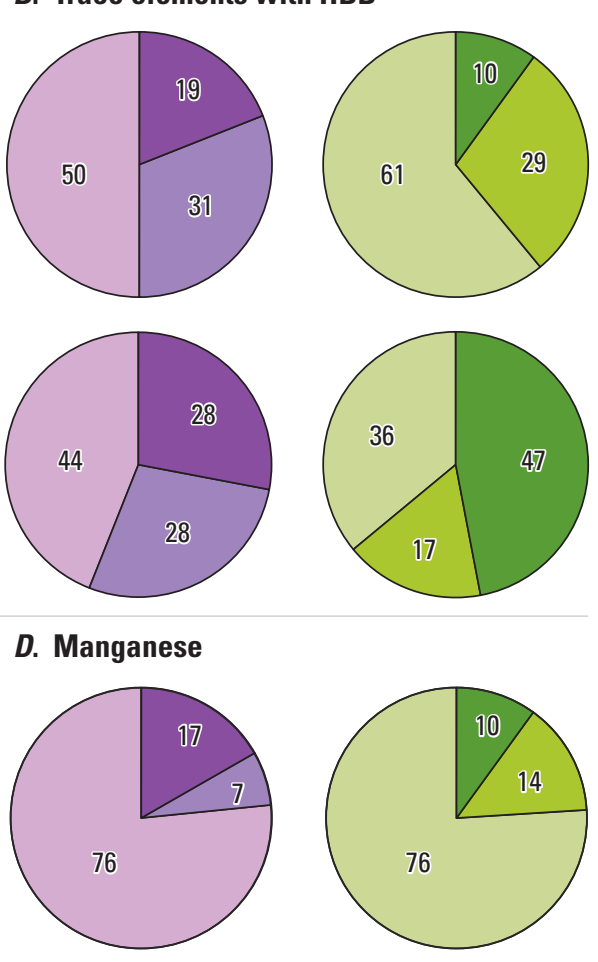

San Francisco Bay Shallow Aquifer
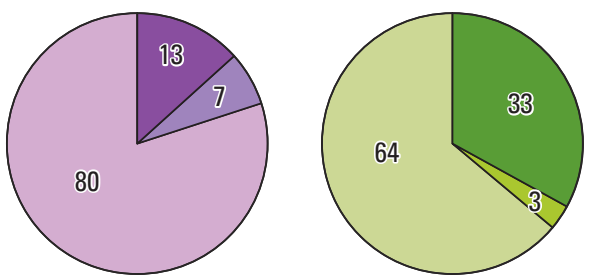


\section{Organic Constituents}

Organic constituents were at concentrations greater than detection limits in about 36 percent of the groundwater resources in the Valleys and Plains study areas of both study units and in 21 percent of the groundwater resources in the Highlands study areas of both study units. The areal proportions of the aquifer in each relative concentration category did not differ significantly between the Highlands study area and Valleys and Plains study area for either of the study units (Bennett, 2018). Organic constituents were at high or moderate relative concentrations in 3 percent of the NSF-SA Valleys and Plains and NSF-PA Highlands study areas. The small proportion of samples in which organic constituents were at high or moderate concentrations was not significantly different between the study areas (contingency table tests $p$ greater than 0.1).

Only two organic constituent classes (defined by a constituent's primary use, solvents for example) trihalomethanes and herbicides-were detected in more than 10 percent of any of the study areas. Carbon disulfide, a natural compound that also has anthropogenic sources, was also detected in more than 10 percent of grid wells in three study areas. Carbon disulfide detections were primarily of natural rather than anthropogenic origin (Bennett, 2018). Trihalomethanes and herbicides were detected more often in the Valleys and Plains study area than in the Highlands of both study units. The only significant difference in detection frequencies between study areas was in the NSF-PA, however, where the frequency of herbicide detection was significantly greater in the Valleys and Plains study area.

\section{Summary}

Comparison of the NSF-PA to the NSF-SA revealed some expected, yet subtle, differences between the respective aquifer systems. With respect to groundwater age, the NSF-PA had a greater proportion of groundwater samples classified as pre-modern than the NSF-SA, whereas the NSF-SA had a higher proportion of samples classified as modern. Significant differences were identified in the frequencies of high relative concentrations between Valleys and Plains study areas of the NSF-PA and NSF-SA for inorganic constituents and trace elements (as constituent classes) and for nitrate and manganese. The detection frequency of organic constituents at high relative concentrations was low in both study units (less than 2 percent in each), and in both study units, the same organic constituent (carbon disulfide) or constituent classes (trihalomethanes and herbicides) was detected at frequencies greater than 10 percent. Lower detection frequencies of organic constituents in the Highlands study area is consistent with less urban land use in the Highlands study area compared to the Valleys and Plains study area.

By George L. Bennett V

\section{REFERENCES CITED}

Belitz, K., Jurgens, B., Landon, M.K., Fram, M.S., and Johnson, T., 2010, Estimation of aquifer scale proportion using equal-area grids-Assessment of regional scale groundwater quality: Water Resources Research, v. 46 , no. 11, W11550, 14 p., http://dx.doi. org/10.1029/2010WR009321.

Bennett, G.L., V, 2018, Status and understanding of groundwater quality in the North San Francisco Bay Shallow Aquifer study unit, 2012; California GAMA Priority Basin Project (ver. 1.1, February 2018): U.S. Geological Survey Scientific Investigations Report 2017-5051, 74 p., https://doi.org/10.3133/sir20175051.

Bennett, G.L., V., and Fram, M.S., 2014, Groundwater-quality data in the North San Francisco Bay Shallow Aquifer Study Unit, 2012 - Results from the California GAMA Program: U.S. Geological Survey Data Series 865, 94 p., https://doi.org/10.3133/ds865.

Forrest, M.J., Kulongoski, J.T., Edwards, M.S., Farrar, C.D., Belitz, K., and Norris, R.D., 2013, Hydrothermal contamination of public supply wells in Napa and Sonoma Valleys, California: Applied Geochemistry, v. 33, p. 25-40, https://doi.org/10.1016/j.apgeochem.2013.01.012.

Jin, S., Yang, L., Danielson, P., Homer, C., Fry, J., and Xian, G., 2013, A comprehensive change detection method for updating the National Land Cover Database to circa 2011: Remote Sensing of Environment, v. 132, p. 159-175, https://www.mrlc.gov/downloadfile2.php?file=Preferred_NLCD11_citation. pdf.

Kulongoski, J.T., Belitz, K., Landon, M.K., and Farrar, C., 2010, Status and understanding of groundwater quality in the North San Francisco Bay groundwater basins, 2004 California GAMA Priority Basin Project: U.S. Geological Survey Scientific Investigations Report 2010-5089, 88 p., http://pubs.usgs. gov/sir/2010/5089/.

\section{For more information}

Technical reports and hydrologic data collected for the GAMA Program may be obtained from:

\section{GAMA Project Chief}

U.S. Geological Survey

California Water Science Center 6000 J Street, Placer Hall

Sacramento, CA 95819

Telephone number: (916) 278-3000

WEB: http://ca.water.usgs.gov/gama

GAMA Program Unit Chief

State Water Resources Control Board Division of Water Quality

PO Box 2231, Sacramento, CA 95812

Telephone number: (916) 341-5779

WEB: http://www.waterboards.ca.gov/gama 